\title{
EURO-COLLINS SOLUTION EXACERBATES LUNG INJURY IN THE SETTING OF HIGH-FLOW REPERFUSION
}

Nuno F. DeLima, MD

Oliver A. R. Binns, MD

Scott A. Buchanan, MD

Michael C. Mauney, MD

Jeffrey T. Cope, MD

Kimberly S. Shockey, MS

Curtis G. Tribble, MD

Irving L. Kron, MD
Single-lung transplantation has been abandoned for the treatment of pulmonary hypertension by many centers because of overperfusion of the graft following implantation. Euro-Collins solution is currently used for lung preservation despite the vasoconstrictive effect of this intracellulartype solution. We hypothesized that high-flow reperfusion, alone or in combination with Euro-Collins-induced vasoconstriction, may cause lung dysfunction. Twenty-eight New Zealand White rabbit lungs were harvested and studied in an isolated, blood-perfused model of lung function after 4 hours of cold ischemia. Control lungs were preserved with $50 \mathrm{ml} / \mathrm{kg}$ cold saline solution flush and reperfused at either normal flow $(60 \mathrm{ml} / \mathrm{min})$ or high flow $(120 \mathrm{ml} / \mathrm{min})$. Experimental lungs were preserved with $50 \mathrm{ml} / \mathrm{kg}$ cold Euro-Collins solution and reperfused at normal or high flow rates. The arteriovenous oxygen gradient at the end of the 30-minute reperfusion period was significantly lower in the high-flow versus the low-flow experimental group ( $31.1 \pm 4.2$ vs $130.6 \pm 41.6 \mathrm{~mm} \mathrm{Hg}, p<0.05)$. The pulmonary vascular resistance was increased in the high-flow groups and the experimental groups, with a statistically significant difference between low-flow experimental and control groups $(64374.4 \pm \mathbf{5 7 2 2 . 6}$ vs $37041.5 \pm 2110.9$ dynes $\cdot \mathrm{sec} \cdot \mathrm{cm}^{-5}, p<0.001$ ). The percentage decrease in dynamic airway compliance in the high-flow experimental group was markedly different from that in the high-flow control group $(-51 \% \pm 13.3 \%$ vs $-10.15 \% \pm$ $3.4 \%, p<0.05$ ). Similarly, the wet/dry ratio of the lungs in the high-flow experimental group $(13.92 \pm 2.32)$ was significantly greater than that in the low-flow experimental group $(6.27 \pm 0.19, p<0.01)$ and than that in the high-flow control group $(5.88 \pm 0.23, p<0.001)$. These data demonstrate that high-flow reperfusion and preservation with Euro-Collins solution are deleterious to lung function, both individually and in combination, in an ex vivo rabbit lung model. Lung preservation with Euro-Collins solution may not be optimal when high-flow reperfusion is anticipated, as in the setting of unilateral lung transplantation for pulmonary hypertension. ( $J$ Thorac Cardiovasc Surg 1996;112:111-6)
D espite the acceptable results now being achieved with clinical lung transplantation, early graft dysfunction is still an important cause of morbidity and mortality. ${ }^{1}$ The mechanism responsible for this primary graft dysfunction is not always apparent, but

From the Division of Thoracic and Cardiovascular Surgery, Department of Surgery, University of Virginia Health Sciences Center, Charlottesville, Va.

This work was supported, in part, by the NIH under RO-1 grant HL 48242 and NRSA fellowship No. 5 F32 HL 08940. Additional support from $\mathrm{CNPq}$-Conselho Nacional de Desenvolvimento Científico e Tecnológico, Brazil.

Received for publication April 18, 1995; accepted for publication Sept. 8, 1995. it is more common in single-lung transplantation for pulmonary hypertension., 3 The diversion of the entire cardiac output to the newly implanted lung results in significant pulmonary hypertension and increased microvascular hydrostatic pressure, leading to edema formation and hypoxemia. Although

\footnotetext{
Address for reprints: Irving L. Kron, MD, Division of Thoracic and Cardiovascular Surgery, Box 310, Department of Surgery, University of Virginia Health Sciences Center, Charlottesville, VA 22908.

Copyright $\bigcirc 1996$ by Mosby-Year Book, Inc.

$0022-5223 / 96 \$ 5.00+0 \quad \mathbf{1 2 / 1 / 6 9 2 5 0}$
} 
this process is potentially reversible, the resultant pulmonary insufficiency occasionally proves fatal.

Lung preservation with Euro-Collins solution (EC) remains the current clinical standard, even in the setting of unilateral lung transplantation for pulmonary hypertension. The high potassium content in this intracellular-type solution is known to induce potent pulmonary vasoconstriction. ${ }^{4}$ In an effort to promote an even distribution of cold EC flush throughout the graft, prostaglandin $\mathrm{E}_{1}\left(\mathrm{PGE}_{1}\right)$ is routinely administered before flush. Although this strategy has shown improvements in EC lung preservation, ${ }^{5}$ unfavorable comparisons with other solutions suggests that EC may not be the ideal preservation solution for the lung. ${ }^{6}$ Moreover, the potassium-induced increase in vascular tone seen with EC may not be completely eliminated by $\mathrm{PGE}_{1}$ administration at reperfusion. ${ }^{7}$

Most studies relating to lung preservation take place in experimental models with normal reperfusion flow rates. Approaching the problem of early graft failure from a different viewpoint, we hypothesized that lung function is impaired by high-flow reperfusion, as occurs with single-lung transplantation in patients with pulmonary hypertension. Our second hypothesis was that the resultant injury is further aggravated by EC-induced vasoconstriction. These hypotheses were investigated by studying lungs after 4 hours of cold ischemia and pretreatment with $\mathrm{PGE}_{1}$ with an isolated, blood-perfused rabbit lung model.

\section{Material and methods}

Lung-heart block harvesting. Twenty-eight New Zealand White rabbits ( 3.0 to $3.5 \mathrm{~kg}$ ) were randomly assigned to four groups of seven animals each. Each rabbit was anesthetized with intramuscular ketamine $(50 \mathrm{mg} / \mathrm{kg})$ and xylazine $(5 \mathrm{mg} / \mathrm{kg})$. All animals received humane care in compliance with the "Principles of Laboratory Animal Care" formulated by the National Society for Medical Research and the "Guide for the Care and Use of Laboratory Animals" prepared by the Institute of Laboratory Animal Resources and published by the National Institutes of Health (NIH publication No. 85-23, revised 1985).

A tracheostomy was performed and followed by paralysis with metocurine $(0.2 \mathrm{mg} / \mathrm{kg})$. Mechanical ventilation was instituted (ventilator RSP1002; Kent Scientific Corporation, Litchfield, Conn.) with room air at a tidal volume of $12 \mathrm{ml} / \mathrm{kg}$ and a rate of 20 breaths $/ \mathrm{min}$. Median sternotomy and thymectomy were then performed. The superior and the inferior venae cavae were loosely encircled with ligatures and the pericardium was opened. Both the pulmonary artery (PA) and aorta were dissected free and similarly encircled. A purse-string suture was then placed in the free wall of the right ventricle, and the rabbit was heparinized $(500 \mathrm{U} / \mathrm{kg})$. After injection of $30 \mu \mathrm{g}$ $\mathrm{PGE}_{1}$ into the PA, the venae cavae were ligated and the time of ischemia onset was charted. The PA was then cannulated through the right ventricular purse-string suture, and both the right ventricular and PA ligatures were tied around the cannula. After venting of the left ventricle and ligation of the aorta, $50 \mathrm{ml} / \mathrm{kg}$ preservation solution at $4^{\circ} \mathrm{C}$ was infused into the $\mathrm{PA}$ from a height of $30 \mathrm{~cm}$. Topical cooling was achieved with cold saline solution slush. During PA flush, the left atrium was cannulated through the left ventricle and a second purse-string suture was tied around the cannula. After the PA flush, the inflow and outflow cannulas were clamped. Care was taken to leave the pleurae intact until completion of the flush, to avoid parenchymal injury. The tracheostomy tube was then clamped at end-inspiration, and the lung-heart block was excised and immersed in cold normal saline solution and then stored at $4^{\circ} \mathrm{C}$.

Assessment of lung function. After 4 hours of storage, the lung-heart blocks were suspended by force transducer in a warmed, humidified tissue chamber (Fig. 1). Ventilation was reestablished with $95 \%$ oxygen and $5 \%$ carbon dioxide at a tidal volume of $12 \mathrm{ml} / \mathrm{kg}$ and a rate of $20 \mathrm{breaths} / \mathrm{min}$. The lungs were reperfused with homologous fresh whole venous blood from a main reservoir. A second venous blood reservoir was used to determine single-pass oxygenation. Blood was harvested from a single rabbit for each experiment. The inflow and outflow cannulas were then connected to the blood-filled perfusion circuit, with care taken to avoid the introduction of air bubbles. The circuit (Kent Scientific) was designed to recirculate $200 \mathrm{ml}$ of warmed blood through a $270 \mu \mathrm{m}$ blood filter (2C7600; I.V. Systems Division, Baxter Healthcare Corp., Deerfield, Ill.) with a roller pump (7521-40; Cole-Parmer Instrument Company, Niles, Ill.) at a rate of 60 or 120 $\mathrm{ml} / \mathrm{min}$, in accordance with the experimental protocol. A $270 \mu \mathrm{m}$ blood filter was chosen to avoid affecting leucocyte or platelet counts. Continuous recordings of PA pressure, pulmonary venous pressure, lung weight, airway flow, and airway pressure were carried out with a dynamic data-acquisition program (Workbench PC; Strawberry Tree, Inc., Sunnydale, Calif.) on a personal computer (470A; Compaq Prolinea, Houston, Texas). This program allowed immediate calculation of pulmonary vascular resistance (PVR), tidal volume, and dynamic airway compliance. The pulmonary venous pressure was maintained within the physiologic range (4 to $8 \mathrm{~mm} \mathrm{Hg}$ ) by setting the appropriate height of a small outflow reservoir in the circuit. Pulmonary venous blood samples were collected for blood gas analysis (Corning $178 \mathrm{pH} /$ Blood Gas Analyser; Corning Inc., Corning, N.Y.) at 10,20 , and 30 minutes after the start of reperfusion; at each sampling time, inflow from the main reservoir was interrupted and the circuit was filled with venous blood from the second inflow reservoir. A $30 \mathrm{ml}$ sample of venous blood was passed through the pulmonary vasculature at each interval to ensure accurate measurement of oxygen content. Oxygen contact with exposed blood surfaces inside the reservoir containers was minimized by the continuous passive infu- 


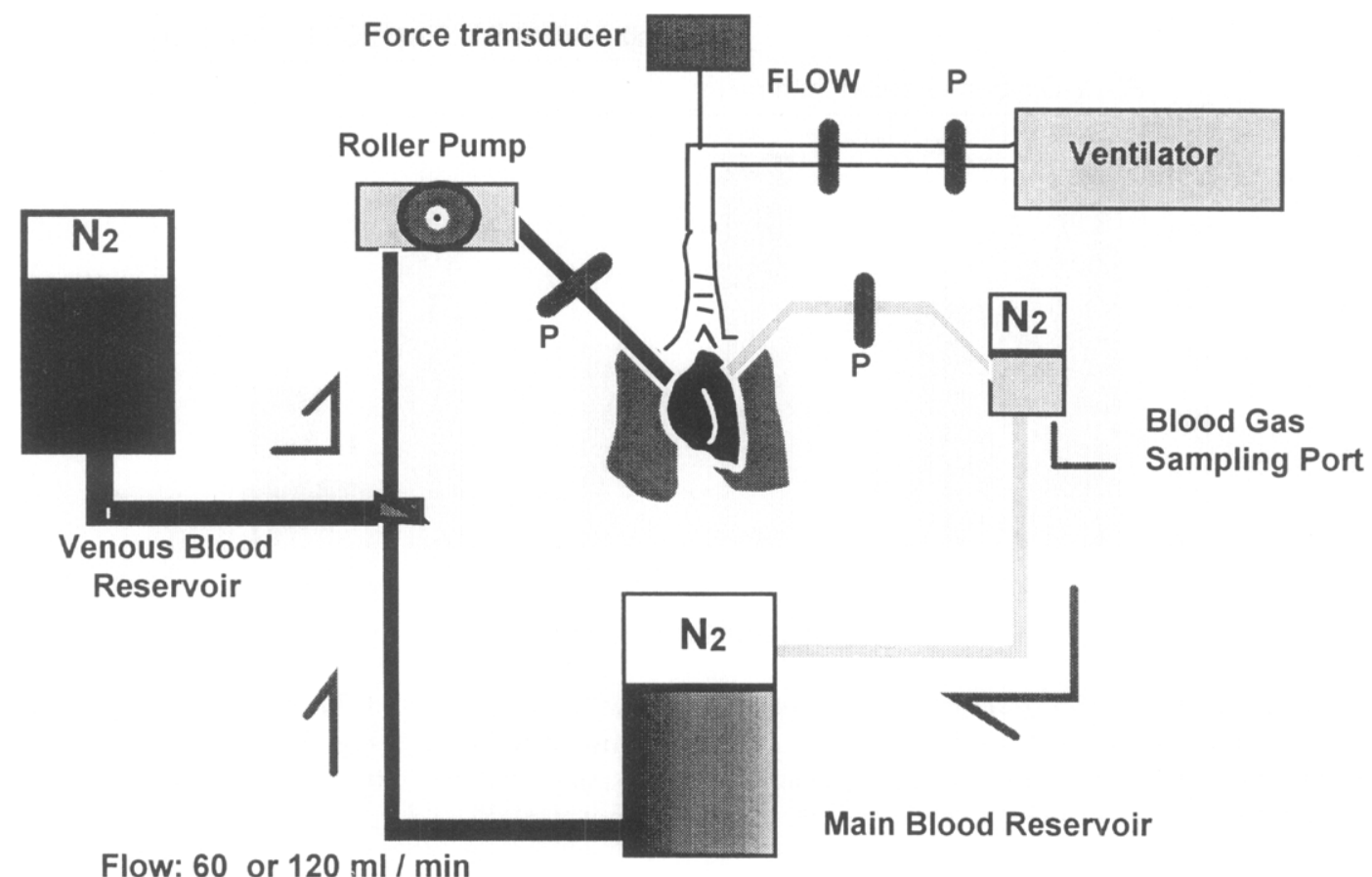

Fig. 1. Schematic of isolated ventilated and blood perfused rabbit lung model. $P$, Pressure transducer; $N_{2}$, nitrogen gas.

sion of $100 \%$ nitrogen. After 30 minutes of reperfusion, lung samples were taken for histologic analysis and calculation of wet/dry weight ratio after passive desiccation.

Experimental protocol. Lungs were flushed with normal saline solution or EC and reperfused at a normal (60 $\mathrm{ml} / \mathrm{min}, \mathrm{S} 60$ and $\mathrm{EC} 60)$ or high flow rate $(120 \mathrm{ml} / \mathrm{min} \mathrm{S} 120$ and EC120; Table I). Saline solution was chosen to rinse the lungs in the control groups because of its inert endothelial effects. Data were obtained every 15 seconds and analyzed at the end of the 30-minute reperfusion period. All values are expressed as mean \pm standard error of the mean.

Statistical analysis was performed by analysis of variance and Kruskal-Wallis nonparametric analysis of variance was used to compare different solutions at the same flow rate and the influence of flow rate on lungs preserved with the same solution. Differences were considered statistically significant if the $p$ value was less than 0.05 .

\section{Results}

There were no significant differences among groups in donor weight, total ischemic time, or hematocrit. Mean hematocrit for all groups combined was $29.53 \% \pm 0.33 \%$. The arteriovenous oxygen gradient at the end of the 30-minute reperfusion period was significantly lower in both highflow groups compared with the normal flow groups
Table I. Experimental protocol and group designations

\begin{tabular}{lcc}
$\begin{array}{c}\text { Group } \\
(n=7)\end{array}$ & $\begin{array}{c}\text { Preservation solution } \\
(50 \mathrm{ml} / \mathrm{kg})\end{array}$ & $\begin{array}{c}\text { Reperfusion flow } \\
(\mathrm{ml} / \mathrm{min})\end{array}$ \\
\hline S60 & Saline & 60 \\
S120 & Saline & 120 \\
EC60 & EC & 60 \\
EC120 & EC & 120 \\
\hline
\end{tabular}

(S120 75.8 \pm 13.0 vs $660284.6 \pm 45.6 \mathrm{~mm} \mathrm{Hg}, p<$ 0.01 ; EC120 $31.1 \pm 4.2$ vs EC60 $130.6 \pm 41.6 \mathrm{~mm}$ $\mathrm{Hg}, p<0.05)$. The arteriovenous oxygen gradient was also lower in the EC groups than in the saline solution groups at the same flow rates, but this difference was not statistically significant (Fig. 2).

The hemodynamic data recorded during reperfusion revealed pulmonary hypertension and increased PVR in the high-flow groups (Table II). These hemodynamic derangements were especially marked in the EC120 group. Fig. 3 demonstrates a continuous tracing of PVR throughout the 30minute reperfusion period for groups $\mathrm{S} 60$ and EC60. Similarly, the percentage decrease in dynamic airway compliance was significant in the EC groups. The lung water content at 30 minutes of reperfusion, 


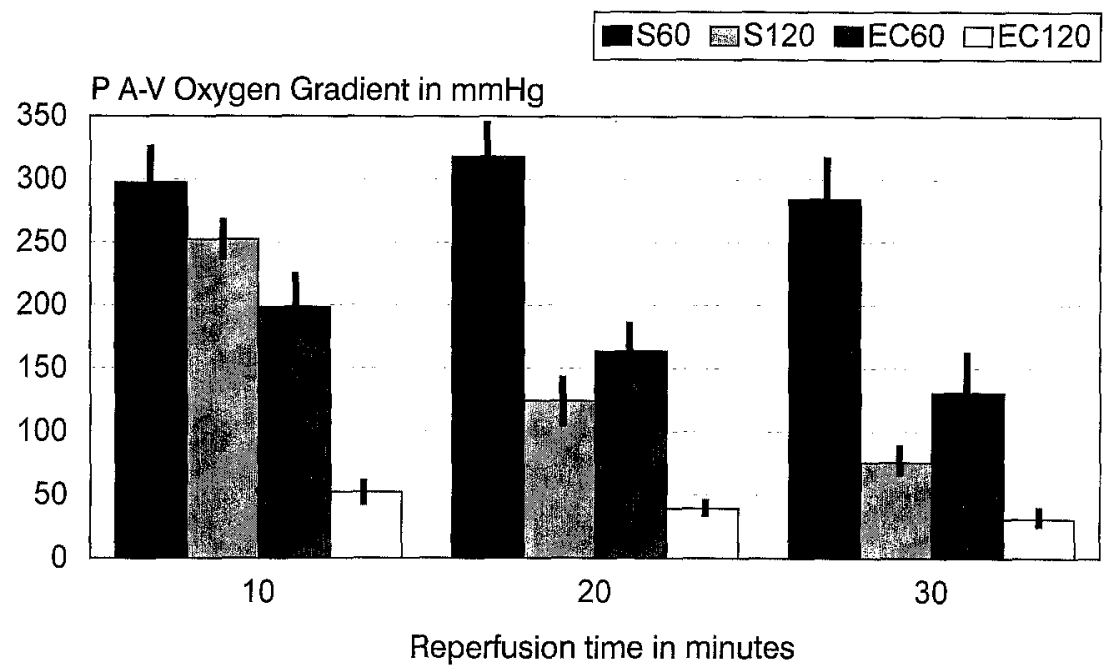

Fig. 2. Pulmonary arteriovenous $(P A-V)$ oxygen gradients at 10,20 , and 30 minutes of reperfusion. Oxygenation declines in high-flow groups and EC groups during reperfusion. All values expressed as mean \pm standard error of the mean (at the end of reperfusion period, $p<0.01 \mathrm{~S} 60$ vs S120; $p<0.05 \mathrm{EC} 60$ vs EC120).

Table II. Results after 30 minutes of reperfusion

\begin{tabular}{lcccc}
\hline Group & $\begin{array}{c}\text { PAP } \\
(\mathrm{mm} \mathrm{Hg})\end{array}$ & $\begin{array}{c}\text { PVR } \\
\left(\text { dynes } \cdot \mathrm{sec} \cdot \mathrm{cm}^{-5}\right)\end{array}$ & $\begin{array}{c}\text { CPL } \\
\text { change (\%) }\end{array}$ & $\begin{array}{c}\text { Wet/dry } \\
\text { rate }\end{array}$ \\
\hline S60 & $34.4 \pm 1.8^{*}$ & $37041.5 \pm 2110.9^{*}$ & $-4.22 \pm 1.9$ & $5.78 \pm 0.1$ \\
S120 & $110.5 \pm 11.6$ & $68197.5 \pm 7627.1$ & $-10.15 \pm 3.4$ & $5.88 \pm 0.23 \dagger$ \\
EC60 & $52.1 \pm 4.9 \ddagger$ & $64374.6 \pm 5722.6 \pm$ & $-23.9 \pm 13$ & $6.27 \pm 0.19 \S$ \\
EC120 & $127.1 \pm 19.9$ & $79848.1 \pm 8412.6$ & $-51 \pm 13.3 \pi$ & $13.92 \pm 2.23$ \\
\hline
\end{tabular}

All data are mean \pm standard error of the mean. $P A P$, PA pressure; $C P L$, dynamic airway compliance.

${ }^{*} p<0.005$ (S60 vs S120).

$\dagger p<0.001$ (S120 vs EC120).

$\neq p<0.001$ (EC60 vs $\$ 60)$.

$\$ p<0.01$ (EC60 vs $\mathrm{EC} 120)$.

$\| \mathrm{p}<0.005$ (EC120 vs EC60).

$\uparrow p<0.05$ (EC120 vs S120).

as expressed by wet/dry ratio, was significantly greater in the EC120 group (Table II).

\section{Discussion}

EC, an intracellular-type preservation solution, was first introduced for renal preservation. Its application to pulmonary transplantation was based on theoretic advantages, such as prevention of cell swelling, conservation of energy stores, and minimization of intracellular potassium loss. ${ }^{8}$ The high potassium concentration of EC depolarizes smoothmuscle cell membranes, however, causing increased vascular tone and ultimately vascular obstruction. ${ }^{9}$ The severe vasoconstriction during pulmonary flush prevents uniform distribution of the solution, resulting in uneven cooling and inadequate preserva- tion. ${ }^{10}$ The administration of $\mathrm{PGE}_{1}$ before PA flush is a routine clinical practice designed to overcome the EC-mediated vaconstriction. This concept was based on experimental studies showing improved pulmonary preservation with $\mathrm{PGE}_{1}$ pretreatment. $^{5}$ Lung preservation with EC or other intracellulartype solutions has, however, led to unpredictable results in lung transplantation. ${ }^{11,12}$ Such varied results may be related to ineffective counteraction of EC-induced vasoconstriction. To evaluate the independent effect of a persistent increase in PVR during reperfusion, we studied lung function after a short cold storage period, thereby minimizing the confounding effects of ischemia-reperfusion injury.

Primary graft failure is of special concern in the 


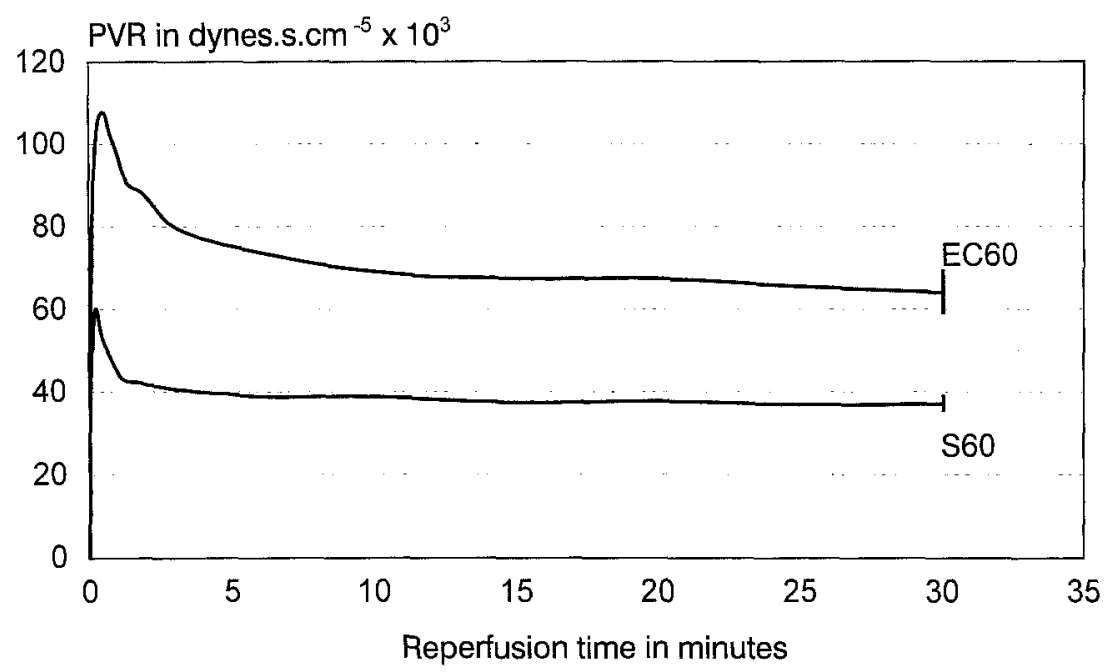

Fig. 3. PVR during 30 minutes in groups reperfused at normal flow. Values are expressed as mean \pm standard error of the mean (at the end of reperfusion period, $p<0.001$ S60 vs ED60).

setting of pulmonary hypertension. Because of donor shortage and high mortality rates for patients with pulmonary hypertension awaiting transplantation, unilateral lung transplantation has been advocated. ${ }^{13}$ In this study, impairment of lung function by high-flow reperfusion was well demonstrated. Lungs preserved with saline solution displayed a decrease in oxygenation, an increase in PVR, and pulmonary hypertension when reperfused at a high flow rate. Despite these detrimental changes, pulmonary edema formation was minimal and dynamic airway compliance was normal. The lungs preserved with EC, however, had not only impaired oxygenation, increased PVR, and pulmonary hypertension, but also severe pulmonary edema formation. This last is demonstrated by a marked decrease in airway compliance and an increased wet/dry ratio. These impairments are evidence of further compromise of lung function, probably as a result of potassiuminduced pulmonary vasoconstriction not effectively counteracted by administration of $\mathrm{PGE}_{1}$.

The PVR data shown in Fig. 3 demonstrate a severe initial increase in the PVR of the group preserved with EC and reperfused at a normal flow rate. PVR stabilized 5 to 10 minutes after a significant decrease, perhaps as the high potassium concentration was washed out during reperfusion. During this period of transient high PVR, however, substantial lung injury can occur. A possible limitation of this rabbit model may be the sensitivity of rodent pulmonary vasculature to high concentrations of potassium, although similar vasoconstrictive effects are seen in human vasculature. Low reperfusion pressure has been shown to attenuate both coronary endothelial and left ventricular dysfunction. ${ }^{14,15}$ It is conceivable that low-flow reperfusion may similarly reduce pulmonary endothelial dysfunction, pulmonary hypertension, and subsequent edema formation. To more effectively mitigate ischemia-reperfusion injury to the lung, which is characterized by an elevation in PVR and an increase in microvascular permeability, ${ }^{16}$ efforts should be directed at preserving not only parenchymal viability but also endothelial function. In addition to the vasoconstrictive properties of $\mathrm{EC}$, other mechanisms resulting in cellular injury may play a role. Solutions with high potassium concentrations have not been unequivocally proved to ameliorate lung preservation; on the contrary, our study provides clear evidence that such solutions can actually be detrimental to pulmonary function.

In conclusion, high-flow reperfusion results in substantial impairment of lung function, which is further potentiated by the high potassium concentration of EC. Just as cardioprotective strategies have evolved and different methods of myocardial protection have been adapted to various clinical situations, alternative solutions and lung preservation methods should be adapted to the clinical condition in lung transplantation. A definite need for further studies with other pulmonary preservation solutions exists, especially in situations were lungs are either injured before procurement or are subjected to abnormal conditions during reperfu- 
sion. Preservation of lung grafts with EC may not be optimal when high-flow reperfusion is anticipated, as in the setting of unilateral lung transplantation for pulmonary hypertension.

We thank Mr. Anthony Herring for his invaluable technical assistance.

\section{REFERENCES}

1. Bando K, Armitage JM, Paradis IL, et al. Indications for and results of single, bilateral, and heart-lung transplantation for pulmonary hypertension. J Thorac Cardiovasc Surg 1994;108: 1056-65.

2. Bando K, Keenan RJ, Paradis IL, et al. Impact of pulmonary hypertension on outcome after single-lung transplantation. Ann Thorac Surg 1994;58:1336-42.

3. Davis RD, Trulock EP, Manley J, et al. Differences in early results after single-lung transplantation. Ann Thorac Surg 1994;58:1327-35.

4. Kimblad PO, Sjöberg T, Massa G, Solem J, Steen S. High potassium contents in organ preservation solutions cause strong pulmonary vasoconstriction. Ann Thorac Surg 1991;52:523-8.

5. Puskas ID, Cardoso PF, Mayer E, Shi S, Slutsky AS, Patterson GA. Equivalent eighteen-hour lung preservation with low-potassium dextran or Euro-Collins after prostaglandin $\mathrm{E}_{1}$ infusion. J Thorac Cardiovasc Surg 1992;104:83-9.

6. Xiong L, Mazmanian M, Chapelier AR, et al. Lung preservation with Euro-Collins, University of Wisconsin, Wallwork, and low-potassium-dextran solutions. Ann Thorac Surg 1994; 58:845-50.

7. Kimblad PO, Steen S. Eliminating the strong pulmonary vasoconstriction caused by Euro-Collins solution. Ann Thorac Surg 1994;58:728-33.
8. Collins GM. Flush preservation. In: Pegg DE, Jacobsen IA Halasz NA, eds. Organ preservation: basic and applied aspects. Lancaster, England: MTP Press, 1982:167.

9. Unruh H, Hoppensack M, Oppenheimer L. Vascular properties of canine lungs perfused with Euro-Collins solution and prostacyclin. Ann Thorac Surg 1990;49:292-8.

10. Yamazaki F, Yokomise H, Keshavjee SH, et al. The superiority of an extracellular fluid solution over Euro-Collins' solution for pulmonary preservation. Transplantation 1990; 49:690-4.

11. Keenan RJ, Griffith BP, Kormos RL, Armitage JM, Hardesty RL. Increased perioperative lung preservation injury with lung procurement by Euro-Collins solution flush. J Heart Lung Transplant 1991;10:650-5.

12. Hardesty RL, Aeba R, Armitage JM, Kormos RL, Griffith BP. A clinical trial of University of Wisconsin solution for pulmonary preservation. J Thorac Cardiovasc Surg 1993;105: 660-6.

13. Pasque MK, Trulock EP, Kaiser LR, Cooper J. Single-lung transplantation for pulmonary hypertension: three-month hemodynamic follow-up. Circulation 1991;84:2275-9.

14. Sawatari K, Kadoba K, Bergner KA, Mayer JE. Influence of initial reperfusion pressure after hypothermic cardioplegic ischemia on endothelial modulation of coronary tone in neonatal lambs. J Thorac Cardiovasc Surg 1991;101:77782.

15. Swanson DK, Myerowitz PD. Effect of reperfusion temperature and pressure on the functional and metabolic recovery of preserved hearts. J Thorac Cardiovasc Surg 1983;86:24251.

16. Allison RC, Kyle I, Adkins KW, Prasad RV, McCord JM, Taylor AE. Effect of ischemia reperfusion or hypoxia reoxygenation on lung vascular permeability and resistance. J Appl Physiol 1990;69:597-603. 